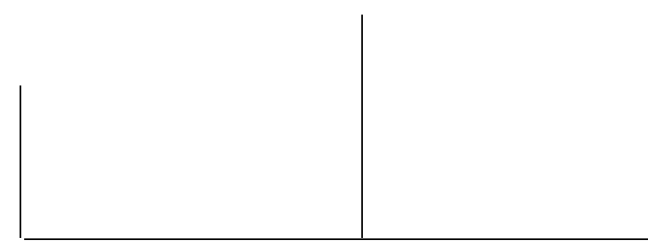

Rev. Latinoam. Psicopat. Fund., VII, 3, 12-25

\title{
Fetichismo e subjetividade feminina
}

\author{
Denise Teles Freire Campos
}

Em seu processo de subjetivação algumas mulheres parecem apresentar uma certa "dificuldade" em ter filhos. Assim, uma demanda incessante de ter um filho é apresentada à medicina (demanda insaciável, visto que ela não se dirige àquilo que exprime) e vem ocupar o lugar de objeto da falta. O jogo do Ter se substitui ao Ser, e permite a permanência dessas mulheres em uma posição de passagem, em uma estrutura fortemente marcada por uma vertente fetichista, que ocupa o lugar da demanda de amor dirigida à mãe. Contrariamente à posição freudiana, pela qual ter um filho permite a resolução final do Édipo, nosso material clínico revela que, nestes casos, o chamado "desejo de ter um filho" responde a uma recusa em subjetivar a falta, recusa em "se tornar mulher", cuja manifestação é uma posição fetichizada.

Palavras-chave: Feminilidade, fetichismo, desejo de ter filhos, subjetivação 
A expressão corrente no campo da reprodução artificial é dada nos termos de "desejo de ter um filho". Sem sombra de dúvida, isto condensa ao mesmo tempo querer gerar um filho de si e carregá-lo dentro de si, dar à luz, e criar um filho, o que significa ter sempre como seu este objeto privilegiado. Já havíamos afirmado anteriormente (Campos, 2000) que, em mulheres sem problemas de engravidar, a distância entre necessidade e desejo, assim como entre desejo de ter um filho e desejo de engravidar somente chegam ao consultório de psicoterapia ou psicanálise - quando chegam - após o nascimento da criança, normalmente em casos de rejeição da criança ou modalidades de depressões associadas à maternidade. No caso de mulheres com dificuldades, estas "distâncias" se colocam durante o tratamento, seja ele psicológico, médico ou analítico.

Em todo caso, o fato de determinadas mulheres apresentarem desejos inconscientes de engravidar e um "repúdio", uma rejeição, ao fato de terem efetivamente um filho, pode significar que a equação filho igual a falo, é, para estas mulheres, uma equação mais longa que a prescrita por Freud. Dito de outro modo, embora pareça haver uma configuração de "tentativa de aceder ao falo paterno", não se pode descartar uma identificação mais primária à mãe (capaz de gerar filhos) associada a uma negação dupla da castração (de si e da mãe, fálica).

\section{O fetichismo como paradigma de compreensão}

Embora, como veremos adiante neste trabalho, tenha sido dominante a idéia da não existência de fetichismo na mulher, as construções teóricas que se seguiram a Freud tornaram o campo desta afirmação bastante flexível. Podemos afirmar que este ponto teórico encontra-se relativamente em aberto, visto que em vários estudos clínicos que se dedicaram aos destinos da libido feminina, se reconhecem ora traços, ora "componentes" fetichistas. Sobretudo este reconhecimento é freqüente no estudo das relações entre mãe e filho. Parece-nos, portanto, 


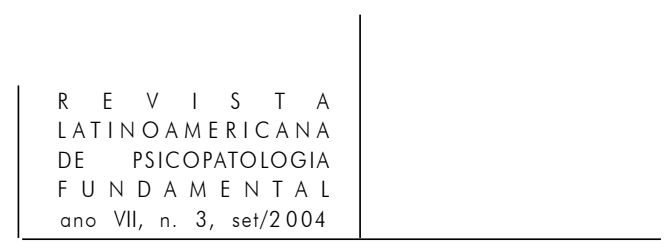

interessante e profícuo propor este "modelo" para interrogarmos o lugar do "desejo de ter um filho" no desenvolvimento libidinal das mulheres, e, em particular, daquelas em que este desejo se apresenta como "irresistível".

Assim, o modelo fetichista como um paradigma, parece-nos particularmente fecundo neste domínio (da feminilidade, do desenvolvimento da libido feminina, da perversão na mulher e do "desejo de ter um filho") onde as construções teóricas e observações clínicas usualmente não parecem convergir em uma direção inequívoca.

A peculiaridade de um paradigma psicopatológico é não apenas requestionar a nosografia, mas comandar mudanças ou remodelamentos tais que surge o risco não desprezível da interpretação sobrepujar a observação dos fenômenos psicopatológicos. (Fédida, 1991, p. 153)

Evidentemente, a vantagem de um paradigma, em psicopatologia, é propor um balizamento para as discussões científicas acerca das conseqüências teóricas de observações, sem, contudo, engessá-las de tal modo a falsear estas próprias observações por interpretações abusivamente excessivas.

\section{A concepção freudiana do fetichismo}

Em seu texto dedicado explicitamente à questão do fetichismo, Freud (1927) alerta para a simplicidade do significado do fetiche: “... o fetiche é um substituto do pênis da mulher (da mãe) em que outrora o menininho acreditou e que (...) não deseja renunciar" (p. 180). Assim, o fetichismo é tido como a recusa da percepção da diferença anatômica entre os sexos, ou seja, recusa da percepção de que a mãe não tem pênis.

A visão do corpo nu de uma mulher adulta (e em especial do corpo nu da mãe) não é suficiente para que a criança acredite que ela não possua um falo. Dentre as vias possíveis, a criança pequena, seja ela do sexo masculino ou feminino, pode desenvolver uma rejeição da castração materna. No entanto, a percepção da ausência de pênis no corpo nu da mulher causa um conflito com o seu desejo de possuir uma mãe fálica. Assim, ela cria um substituto do falo maternal, fazendo um compromisso entre a angústia da percepção e o desejo.

Em "Três ensaios sobre a teoria da sexualidade”, Freud (1905) diz: “... o que leva a substituição do objeto pelo fetiche é uma conexão simbólica de pensamentos que, na maioria das vezes, não é consciente para a pessoa" (p. 145).

A estrutura "fetichista" pode ser então compreendida como uma dada configuração, resultante da dinâmica recíproca entre complexo de castração e 


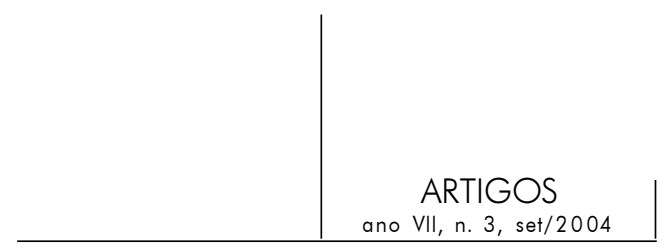

complexo de Édipo. Uma configuração na qual se distingue inicialmente um processo de divisão do ego, resultante do momento em que o ego deve se confrontar ao reconhecimento de um perigo "real" (ameaça de castração) e renunciar à satisfação instintual, ou rejeitar a "realidade", e convencer-se de que não há perigo e continuar a satisfação. Em alguns casos, porém:

... a criança não toma nenhum destes cursos, ou melhor, toma ambos simultaneamente (...) Por um lado, com o auxílio de certos mecanismos, rejeita a realidade e recusa-se a aceitar qualquer proibição; por outro, no mesmo alento, reconhece o perigo da realidade, assume o medo desse perigo, como um sintoma patológico... (Freud, 1940[1938], p. 309)

A ameaça "da realidade" a qual Freud se refere é a ameaça de castração no menino, e as duas tendências terão sua cota, por meio de uma solução de compromisso (entre a angústia da percepção e o desejo): o instinto pode ser satisfeito e a "realidade" respeitada, ao preço de uma fenda no ego. Esta operação permite que a referência do pênis no corpo masculino (pois se trata aqui do menino) seja preservada, ao mesmo tempo em que ele transfere a importância do pênis da mãe para outro lugar do corpo feminino. Assim ele reconhece a castração da mãe, sem desistir da mãe-fálica e da satisfação a ela associada. Deste modo, o menino "criou um substituto para o pênis que sentia falta nos indivíduos do sexo feminino, o que equivale dizer, um fetiche” (p. 311).

O substituto do falo criado pela criança, nesse momento, vem ocupar o lugar da angústia, ou seja, a angústia da castração, fazendo com que o sujeito permaneça em um estado primário do seu desenvolvimento sexual. A obtenção do prazer não se dá com o objeto, posto que este foi substituído por outro, mas sim na fantasia onde o objeto permanece inalterado. $\mathrm{O}$ aspecto essencial da angústia da castração "consiste no fato de que, pela primeira vez, a criança reconhece, ao preço da angústia, a diferença anatômica entre os sexos" (Nasio, 1995, p. 13).

Segundo Perrier (1967) a angústia da castração não está ligada a eventuais convivências precoces da realidade sexual, ou à promiscuidade do não-pudor da mãe ou da avó; a castração só adquire sentido como revelação secundária da ausência, na mulher amada do signo que envia ao desejo do Outro.

O substituto remete ao objeto, é por meio dele que o objeto se faz presente, mas ele não é a fonte do prazer, senão o que ele representa. Entretanto, segundo Freud (1905), existem graus diferentes de fetichismo que vão desde a normalidade, como nos casos de amor, nos quais os amantes trocam pequenos pertences como forma de se fazerem presentes, aos casos ditos patológicos, aqueles em que o anseio pelo fetiche se fixa, ocupando o lugar do alvo sexual normal, e também se desprende da pessoa e se torna um único objeto sexual. 


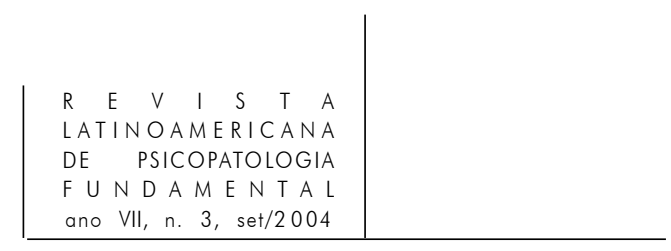

A propósito da natureza da escolha do sintoma, Lacan (1958) alerta para o cuidado em estabelecer a relação entre recalcamento, fase fálica e fetiche:

Deste modo, alguns autores foram levados a considerar a fase fálica o efeito de um recalcamento, e a função que dele toma o objeto fálico, sintoma. A dificuldade começa quando se trata de saber qual sintoma: fobia, diz um, perversão diz outro, e às vezes, o mesmo. Parece que, quanto a este último caso nada mais está claro: não que não existam interessantes transmutações do objeto de uma fobia em fetiche, mas justamente, se eles são interessantes, eles o são pela diferença do lugar que ocupam na estrutura. (p.105)

Uma tal configuração, somente é possível porque, segundo Freud (1927), não se trata de um recalcamento, no sentido exato, mas de uma recusa da realidade, ao preço de uma divisão do ego: a percepção continua a existir, mas é alvo de uma ação enérgica de rejeição. Esta recusa se refere, em primeiro plano, à recusa em reconhecer a diferença entre os sexos (Aulagnier, 1990).

Para Freud, recusa e recalcamento não são conceitos completamente separados, sendo a primeira uma especificação do segundo. Embora o termo recusa carregue uma relativa ambigüidade, acentuada frente ao termo foraclusão, e ainda, na língua francesa pela denegação, Valabrega (1990) afirma que não se trata de pura questão lingüística, mas de compreender que, no fetichismo, a diferença dos sexos, a ausência de pênis na mulher (com a conseqüente fantasia de castração) não são completamente negligenciadas: são, simultaneamente, reconhecidas e negadas.

Assim, a formulação freudiana pode ser lida mais claramente: o fetiche é o substituto do pênis da mãe. Se retornarmos à equação "filho igual a pênis" ou "filho igual a falo", fica claro que o fetiche pode ser compreendido como o substituto do falo materno.

\section{A identificação primária à mãe}

Freud (1932), nos fala da ambivalência da identificação, em que a distinção fundamental estaria entre ser e ter o pai (no caso do menino). Mas ele diz ainda que o mesmo se aplica à menina com as substituições necessárias, ou seja, à identificação com a mãe, em que a distinção seria em se ligar ao sujeito ou ao objeto do ego. A identificação ao sujeito é mais primária, antes mesmo de qualquer escolha sexual de objeto; neste caso "a identificação esforça-se por moldar o próprio ego de uma pessoa segundo o aspecto daquele que foi tomado como modelo" (Freud, 1921, p. 134). 


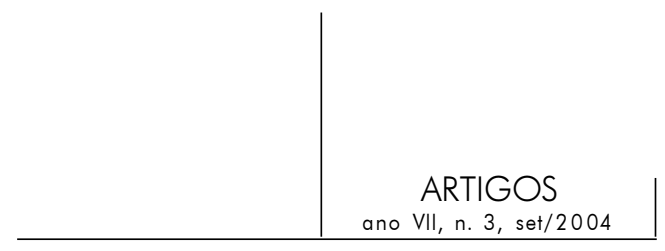

A fórmula da distinção entre a identificação com o pai e a escolha deste como objeto, não constitui obstáculo a uma melhor compreensão. No primeiro caso, o pai é o que gostaríamos de ser; no segundo, o que gostaríamos de ter, ou seja, a distinção depende de o laço se ligar ao sujeito ou ao objeto do ego. $\mathrm{O}$ primeiro tipo de laço, portanto, já é possível antes que qualquer escolha sexual de objeto tenha sido feita. É muito mais difícil fornecer a representação metapsicológica clara da distinção.

Os mecanismos segundo os quais a identificação e o investimento de objeto se distinguem na menina não foram suficientemente teorizados e são ainda pouco conhecidos até hoje. Na nossa perspectiva, tomando como referência o conjunto de nossas interrogações e trabalhos, condensadas sob a expressão "desejo irresistível de ter um filho", esta identificação das mulheres às suas mães, identificações escutadas nos dispositivos psicanalíticos, assim como manifestações inconscientes de uma rivalidade extrema para com estas mesmas mães, estão associadas a um processo de identificação que tem por fundamento o período pré-edipiano.

Os estudos realizados neste campo não hesitam em assinalar os elos clínicos entre o chamado "desejo de ter um filho" e uma rivalidade para com a mãe. Uma vez que a mãe é sentida como uma rival, o fato de esta "rival" já ter dado um filho ao pai (a própria filha em questão), a dificuldade ou incapacidade em engravidar toma o valor de falta. Também neste sentido, ela se sente diminuída face à sua rival. Esta falta se sobrepõe a uma outra: a de não ter pênis. Assim, ela não pode ser nem como seu pai (visto que não tem pênis), nem como sua mãe (visto ser "incapaz" de ter filhos).

Do mesmo modo, vários autores que estudam o desejo de ter um filho, no contexto das PMA's (Procriações Medicalmente Assistidas), tomam posição em favor de uma interpretação clínica da função da criança solicitada como sendo objeto imaginário que fantasiosamente viria preencher ou curar uma ferida narcísica. Entretanto, uma questão se impõe: esta ferida narcísica ocorre em qual nível de narcisismo, aquele da imagem do eu, cujo modelo ideal de mulher seria a imagem da "mãe onipotente", portanto, o narcisismo relativo ao ideal do ego estruturado e referente à trama edipiana; ou, em outro nível, a ferida teria um referente mais arcaico, no qual o eu e o objeto de investimento libidinal não estariam ainda distintos. Neste segundo caso, a expressão "mãe onipotente", não pode ser considerada pertinente para falar de um objeto fantásmico completo, perfeito. Devemos aqui recordar que Freud (1922) afirma a identificação como a manifestação mais precoce de uma ligação afetiva com outra pessoa. A identificação primária opera em um estádio no qual sujeito e objeto não estão diferenciados e constitui um dos processos fundamentais que permitam a formação do ego pela incorporação dos atributos do objeto. 


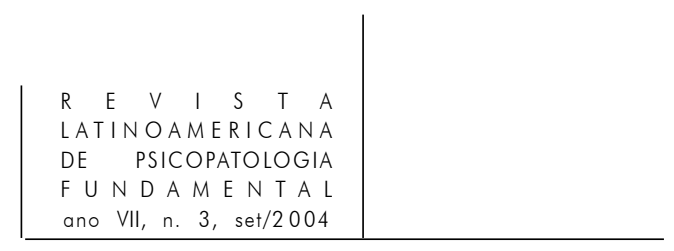

Com a chegada do período edipiano, as relações entre mãe e filha são caracterizadas por uma "reprovação" inflexível da filha contra a mãe. A menina deve se confrontar a duas impossibilidades: a de ter a mãe como objeto de amor e a de partilhar a experiência feminina, dado que elas "partilham" a falta de um significante comum. E, ainda, a menina atribui à mãe a responsabilidade de "não tê-la feito com um pênis". Este estado de desarmonia é vivido com grande sofrimento, de tal modo que os pesquisadores cunharam a expressão "devastação". Lacan (1973) assinalou este estado de coisas afirmando "o quanto as relações entre mãe e filha podem ser devastadoras". Também Azambuja (1993), Chatel (1993) e Paron (1993) destacam estas particularidades da relação entre mãe e filha: "Eu preservarei esta palavra 'devastação' para designar a especificidade da relação mãe-filha e chamarei de 'praticar a devastação', os modos pelos quais cada uma delas se confrontará efetivamente à impossível harmonia, obrigadas ambas a reconhecer o muro ao qual elas se bloqueiam" (Chatel, 1993, p. 61).

Evidentemente, no caso de mulheres com dificuldade de engravidar, a rivalidade com a mãe (quer ela seja devastadora ou não) é também a expressão de um retorno da relação primária com a mãe. Seja ela expressa como uma acusação (a de ter feito a filha com o "defeito" de não poder ter filhos; "defeito" de não ter pênis) ou como prova de amor ao pai (para quem a mãe já deu suas provas de amor, já lhe deu um filho), a rivalidade significa "um retorno à mãe".

Neste panorama clínico, diversos trabalhos associam o "desejo de ter um filho" a uma identificação extrema das pacientes com sua mães. Embora uma boa parte destes estudos situem a identificação no plano dos conflitos edipianos e na esfera do ideal do ego ("ser mãe" equivalendo a "ser mulher", no ideal do ego feminino), Chatel (1993) e Delefosse (1995) abrem uma outra perspectiva, na qual entrevemos a coabitação de uma identificação tardia (datada do período da formação do superego, então, pós-edipiana) e uma outra identificação mais constitutiva, uma identificação primária da menininha com sua mãe.

Assim, parece-nos pertinente assinalar uma feminilidade que não se constrói em referência à "inveja do pênis". Pode-se pensar na condensação de dois movimentos: a identificação à mãe-falo (identificação primária) e o ódio à mãemulher (possuidora do falo paterno), cujo avatar é a identificação ao pai.

Mesmo na forma considerada por Freud (1931), como a "forma feminina do complexo de Édipo", o filho vem "cauterizar" a ferida narcísica aberta pelo complexo de castração e selar a escolha de objeto para além do ser masculino concreto que é o pai. Se, na terceira via de desenvolvimento proposta por Freud, se faz possível a "realização da inveja do pênis", a gravidez está ainda situada no gozo fálico.

Podemos pensar, assim, numa identificação primária com a mãe como forma de ser mulher. Desta forma, uma identificação posterior com o pai seria somente 


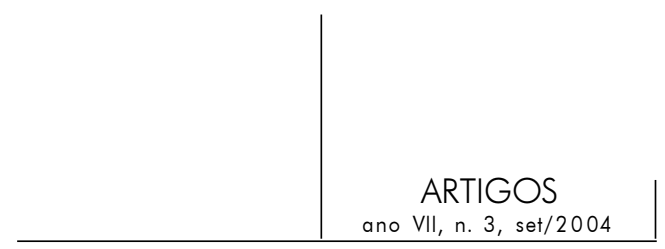

como uma via de alcance da mãe, posto que a mãe busca no pai aquilo que ela, enquanto mulher, não tem. Stein diz: "Não saberíamos, então, nos identificar ao falo sem se fazer falo de alguém” (Stein, 1987, p. 227).

Desta forma, para que a mulher possa ter o seu próprio falo, ela deve conseguir ser o falo da mãe. É por este viés que a menina divide o segredo com a mãe e aprende com ela como é ser mulher. Na verdade, parece-me que Freud já pressentia uma função anterior ao Édipo, uma equação maior: a menina já vem deslizando no interior de uma longa equação:

Vemos, portanto, que a fase de ligação exclusiva à mãe, que pode ser chamada de fase pré-edipiana, tem nas mulheres uma importância muito maior do que a que pode ter nos homens. Muitos fenômenos da vida sexual feminina, que não foram devidamente compreendidos antes, podem ser integralmente explicados por referência a essa fase. (Freud, 1931, p. 265)

Partindo desse ponto, podemos assinalar, então, uma feminilidade que não se constrói em referência à "inveja do pênis", mas sim de uma identificação à mãe-falo, em que a menina aprende com a mãe como é ser mulher. Mesmo que para isto tenha que haver uma relação ambivalente à mãe-mulher, pela negação da sua castração, e de uma demanda de amor, idealizado (fantasiado), não correspondido.

A permanência de uma identificação primária "não-recalcada" para com a mãe, na mulher, desloca a questão do valor simbólico da equação segundo a qual o filho seria o substituto do falo, uma vez que um filho poderia se inscrever antes na lógica de uma negação da castração materna, pois da sobrevivência da mãe-fálica, com quem a menina permanece identificada sob um modo primário, por assim dizer, fusional ou identitário, em relação à identidade feminina.

\section{Perversão e fetichismo na mulher}

Roudinesco e Plon (1998), assinalam, em seu comentário acerca do verbete "fetichismo", que a tese da inexistência do fetichismo, bem como das perversões nas mulheres, era plenamente aceita pelos médicos do início do século XX. Entretanto, desenvolvimentos posteriores, tanto na escola de influência inglesa, pelos seguidores de Klein, quanto na escola de influência francesa, pelos de Lacan e seguidores, acabaram por derrubar esta aceitação plena, colocando em seu lugar a constatação de quanto a mulher foi negligenciada ou mal-compreendida pela psicanálise do início do século.

Uma questão que é retomada por Clavreul (1990), que aponta que o reconhecimento da ausência de pênis na mãe, ocorre para o menino sob o fundo 


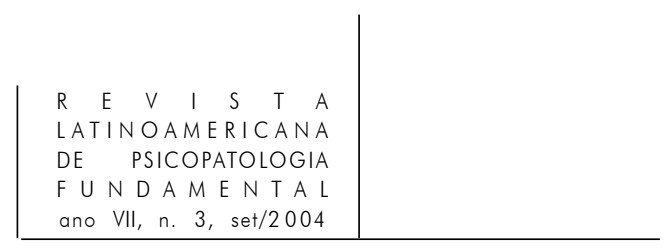

da presença para ele, mas tanto para a menina quanto para o menino, sob o fundo de uma fantasia partilhada da presença de pênis em todos os seres; assim, um ponto central da castração é o da aquisição do saber sobre a ausência, aquisição que se faz ao preço de intensas lutas internas. Deste modo, um aspecto fundamental do reconhecimento da diferença entre os sexos está na descoberta, pelo sujeito, qualquer que seja seu sexo biológico, que sua posição subjetiva anterior repousava principalmente num saber errôneo, saber enganador:

... e essa descoberta é plena de ensinamentos a respeito do que é a fragilidade de uma posição subjetiva, pois se trata não apenas de ter de conhecer uma particularidade anatômica singular, porém contingente, mas também de ter de integrar o fato de que apenas a ausência pode ser causa do desejo. (Clavreul, 1990, p. 127)

Exatamente este ponto constitui, para o autor, a particularidade da formação perversa, pois para o perverso: não é uma falta que é a causa do desejo, mas uma presença (o fetiche). Assim, a descoberta da diferença entre os sexos deveria ser a ocasião de uma re-interpretação relativa à causa do desejo e "definitivamente, esta reintegração faltou ao perverso" (ibid.). Então, para o perverso, coloca-se sempre a necessidade de transgredir uma lei, ou para além disto, ele recusa a "lei" da castração para tentar substituí-la pela lei do seu desejo. Assim, o objetofetiche constitui a presença que o perverso deseja impor para anular a ausência (e o reconhecimento da ausência como causa do desejo).

Por tal, vários autores (Rosolato, 1990; Valabrega, 1990; Perrier, 1967; Granoff \& Perrier, 1991) não hesitam em propor o "modelo" fetichista como paradigma teórico importante para a compreensão de todas as perversões. Esses autores assimilam incontestavelmente o fetichismo à esfera da perversão; o que não constitui uma posição freudiana, segundo a qual o fetiche não corresponde nem à repressão de um fragmento do id, pelo ego e à serviço da realidade, nem corresponde ao "desligamento" de um fragmento de realidade, mas sim a um processo de divisão do ego.

A tese de que o fetichismo pode ser considerado um paradigma deve ser sempre tratada com uma grande flexibilidade, posto que não parece claro, nem em Freud, nem segundo nosso ponto de vista, e ainda de outros, que ele seja aplicável somente às perversões. Em um texto dedicado exatamente ao estudo das perversões sexuais a partir do fetichismo, Valabrega (1990), inicia seu argumento afirmando a estrutura distinta do fetichismo e seu "pertencer indiscutível às perversões sexuais" e, no entanto, finaliza ampliando a importância do mesmo em outros quadros:

E se observarmos que o fetichismo pode servir de ponto de referência para as neuroses, por exemplo as fobias, a hipocondria de castração (...) ou as 


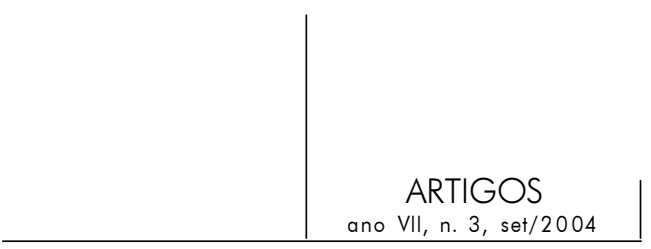

psicoses, principalmente a paranóia e a maníaco-depressiva, se suas relações com a criação artística, com o sagrado e a sublimação vierem a ser estabelecidas, tal posição privilegiada nada teria de abusiva. (Rosolato, 1990, p. 48)

Tal "ampliação" se justifica em Rosolato (1990) por uma ênfase do mecanismo de sppliting do ego, como estrutura que deve ser melhor investigada.

Podemos então retomar o que constitui uma certa configuração, que constitui um "modelo" do fetichismo, composta de três elementos, a saber: a sobrevivência fantásmica do pênis da mãe; uma recusa, como mecanismo que permite que a diferença entre os sexos seja, ao mesmo tempo, negada e reconhecida; e uma divisão do ego, que permite o processo de recusa. O que nos leva a uma segunda questão: a da existência de fetichismo na mulher.

$\mathrm{O}$ estudo coerente da relação entre fetichismo e feminilidade apresenta dificuldades mais profundas. Primeiro, pela deficiência de uma teorização sólida e satisfatória do destino feminino da libido e, em segundo, pela falta de uma definição irrefutável da estrutura perversa (Granoff \& Perrier, 1991). Entretanto, uma abertura é assinalada por Roudinesco e Plon (1998): ao analisarem os desenvolvimentos da escola francesa, apontam que para os autores se apoiando nesta linhagem, o fetichismo não existirá entre as mulheres "sob a forma da construção de um objeto-fetiche". Nas mulheres, a relação com o objeto libidinal será a base para a construção da "estrutura fetichista".

Dentro deste contexto, Granoff e Perrier (1991) afirmam, a propósito do desenvolvimento homossexual feminino, que a menina pode "insistir", contra tudo e contra todos, que ele possui o falo, ela se torna imagem (representante) do falo e se oferece (na relação homossexual) à sua mãe (na figura de uma outra mulher):

... o que acontecerá não será em absoluto a representação das relações do pai com a mãe. Posto que ela não está no lugar do pai. Ela construiu este personagem fictício "fetichizado", inteiramente engajado na representação da falta de seu primeiro objeto de amor, que ela reencontra em sua parceira. (Granoff et Perrier, 1991, p. 86-7)

É de se notar que, se de um lado a possibilidade de uma estrutura fetichista, com a construção inequívoca de um "objeto-fetiche", é absolutamente descartada para as mulheres, de outro a existência de uma vertente perversa e fetichista (um versant perverso) é, sem hesitação, reconhecida. Assim, o objeto fetiche é marcado por se constituir um certo "prolongamento" simples do corpo da mãe, que se liga ao objeto, mas dissimula o sexual, "mesmo a mulher e o pênis podem desempenhar este papel" (Rosolato, 1990, p. 25). Metaforicamente, o ser mulher se equivalendo a ser capaz de ter filhos também pode ser como um prolongamento, o ser mulher pode ser fetichizado, ocupando o papel de um 


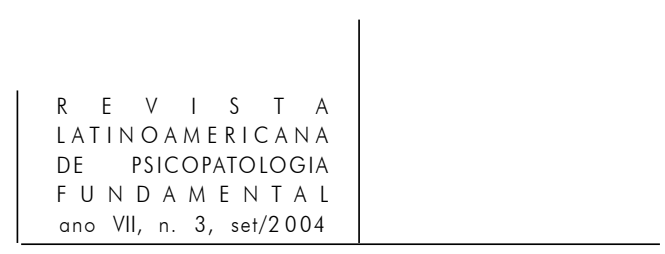

componente fetichista da relação entre mãe e filha. O mesmo "componente fetichista" deve ser interrogado no caso das mulheres que se prestam ao prazer dos fetichistas, pois, como assinala Clavreul (1990), pouco importa se esta parceira finja gostar ou apenas se submeta às práticas do perverso, o que está em jogo é o fascínio que este último exerce, de tal modo que a parceira sofra igualmente da lei do fetiche, que substitui a lei da diferença entre os sexos (a ausência de pênis na mãe) como causa do desejo.

Como componente ou como analogia, também para Granoff e Perrier (1991) a relação entre mãe e bebê é susceptível de derivar em uma relação perversa "do tipo análogo à perversão fetichista" à condição que o bebê (objeto real) se torne, para a mãe, uma tela sobre a qual ela projeta a falta (ausência) que é causa de seu desejo, para além de seu objeto de amor. Não é, portanto, surpreendente que os autores afirmem que é raro que a relação entre uma mãe e seu bebê não participe, de algum modo, deste tipo de relação (perversa, do "tipo fetichista"). Podemos pensar que, obviamente, isto se reaproxima da posição freudiana de um certo fetichismo da vida cotidiana.

\section{Em defesa de um paradigma}

A proposição do fetiche como paradigma de compreensão do chamado "desejo de ter um filho", permite retomarmos nossa questão central, inicialmente formulada nos seguintes termos: a negação da castração materna pode levar a menina à formação de um fetiche como forma provisória de resolução do complexo de Édipo, particularmente em mulheres apresentando um "irresistível desejo de ter um filho"? Evidentemente, os termos deste problema podem ser focados de outro prisma: existiria um componente fetichista inerente à "resolução" do complexo de Édipo feminino, associado ao "desejo de ter um filho" e à sobrevivência do falo materno e do elo primário de amor que lhe dá existência?

O "desejo de ter um filho" (com ou sem sucesso é importante salientar) é apresentado insistentemente, como uma repetição, como desejo "irresistível" e "maior do que tudo", nunca satisfeito, e pode representar, nestes casos, o "objeto" fetiche cujo valor está além do "objeto" em si:

O que é essencial na teoria freudiana do fetichismo? Sem dúvida a identificação da problemática fálica, a problemática da castração como ela se inscreve no fetiche. E, de outro lado, o estatuto do próprio fetiche em si mesmo, o qual podemos considerar, com Lacan, um significante. (Chemama \& Vandermersch, 1998, p. 135) 


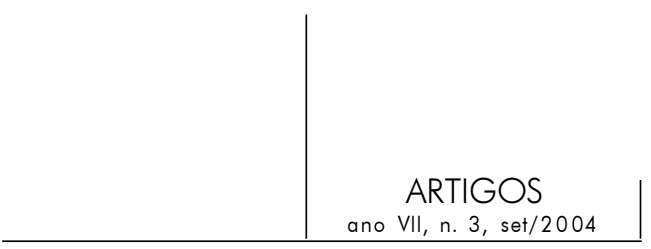

Referências

Aulagnier-Spairani, Piera. Remarques sur la féminité et ses avatars. In: Le désir et la perversion. Paris: Seuil, 1990. p. 53-79.

Azambuja, Sônia Curvo. Notas sobre o feminino. In: Em busca do feminino. São Paulo: Casa do Psicólogo, 1993. p. 79-85.

CAmpos, Denise Teles Freire. Mãe e filha: da identificação à devastação. Pulsional Revista de Psicanálise, São Paulo, ano XIII, n. 135, p. 5-13, jul./2000.

Chatel, Marie-Magdeleine. Malaise dans la procréation. Paris: Albin Michel, 1993.

Chemana, Roland et VAndermersch, Bernard. Dictionnaire de la psychanalyse. Paris: Larousse, 1998.

Clavreul, Jean et al. O casal perverso. In: O desejo e a perversão. Campinas: Papirus, 1990. p. 113-55.

Delefosse, Marie Santiago. Fécondation in vitro, demande d'enfant et pratiques médicales. Paris: Anthropos, 1995.

FÉDIDA, Pierre. Nome, figura e memória. A linguagem na situação psicanalítica. São Paulo: Escuta, 1991.

FREUD, Sigmund (1905). Três ensaios sobre a teoria da sexualidade. In: Edição Standard das Obras Psicológicas Completas. Rio de Janeiro: Imago, 1987. p. 118-216. v. VII. (1921). Identificação. In: Edição Standard Brasileira das Obras Psicológicas Completas. Rio de Janeiro: Imago, 1987. p. 133-40. v. XVIII. (1922). Le moi et le ça. Oeuvres Complètes. Paris: PUF, 1991. v. XVI.

(1927). Le fétichisme. In: La vie sexuelle. Paris: PUF, 1995. p. 133-8.

(1931). Sur la sexualité féminine. In: La vie sexuelle. Paris: PUF, 1995. p. 138-55. (1932). Nouvelles conférences d'introduction à la psychanalyse. Paris: Gallimard, 1989.

(1940). A divisão do ego no processo de defesa. In: Edição Standard Brasileira das Obras Psicológicas Completas. Rio de Janeiro: Imago, 1990. p. 305-12. v. XXIII.

Granoff, Wladimir \& Perrier, François. Le désir et le féminin. Paris: Aubier, 1991.

LACAN, Jean-Jacques (1958). La signification du phallus. In: Écrits II. Paris: Seuil, 1994. p. 103-15.

Conférences américaines. Paris: Seuil, 1973.

NAsıo, Juan David. Lições sobre os sete conceitos cruciais da psicanálise. Rio de Janeiro: Jorge Zahar, 1995.

Paron, Edoarda Anna Giuditta. O mito da identidade feminina. In: Em busca do feminino. São Paulo: Casa do Psicólogo, 1993. p. 99-107. 
PerRier, François. De l'érotomanie. In: Le désir et la perversion. Paris: Seuil, 1967. p. 127-151.

Rosolato, Guy. Étude des perversions sexuelles à partir du fétichisme. In: Le désir et la perversion. Paris: Seuil, 1990. p. 7-40.

Roudinesco, Elizabeth et Plon, Michel. Dicionário de psicanálise. Rio de Janeiro: Jorge Zahar, 1998.

Stein, Conrad. L'enfant imaginaire. Paris: Denoël, 1987.

VAlabrega, Jean-Paul. Le problème anthropologique du phantasme. In: Le désir et la perversion. Paris: Seuil, 1990. p. 91-117.

\section{Resumos}

En su proceso de subjetivación algunas mujeres suelen presentar una cierta "dificultad" en tener hijos. Cuando esto ocurre, una incesante demanda de tener un hijo llama a la puerta de la medicina (demanda insaciable, visto que ella no se dirige a aquello que ella expresa) y viene a ocupar el lugar de objeto de la falta. El juego del Tener substituye al del Ser y permite la permanencia de estas mujeres en una posición de tansición, en una estructura marcada por una vertiente fetichista, que viene a ocupar el lugar de una demanda de amor dirigida a la madre. Contrariando la tesis freudiana según la cual el tener un hijo permite la resolución final del complejo de Edipo, nuestro material clínico revela que, en estos casos, el conocido "deseo de tener un hijo" responde, en realidad, a una recusa a subjetivar la falta, recusa de "llegar a ser mujer", cuya manifestación es una posición fetichizada.

Palabras claves: Feminidad, fetichismo, deseo de tener hijos, subjetivación

Certaines femmes semblent présenter dans leur processus de formation de la subjectivité, une "difficulté" à avoir des enfants. Ainsi une demande insistante est dirigée vers la médecine (demande insatiable du fait qu'elle ne se tourne pas vers ce qu'elle exprime); elle vient occuper la place de l'objet du manque. L'enjeu de l'Avoir est remplacé par celui de l'Etre, ce qui permet à ces femmes de rester dans une position de passage, dans une structure à fort versant fétichiste; position qui occupe la place de la demande d'amour dirigée vers la mère. En opposition à la position freudienne, selon laquelle avoir un enfant (un garçon surtout) permet la disparition du complexe d'Edipe, notre matériel clinique semble indiquer que, dans ces cas en particulier, le dit "désir d'avoir un enfant" répond à un refus de symboliser le manque, refus à "devenir femme", dont la manifestation est une position fétichisée.

Mots clés: Fétichisme, subjetivation féminine, "Désir d'enfant" 


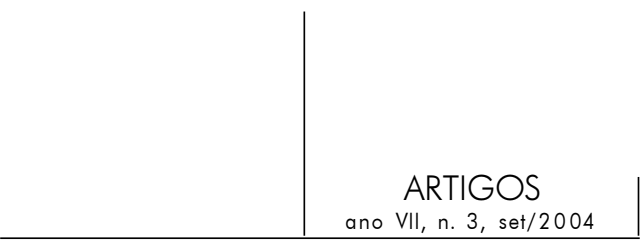

In their process of subjectivation, some women seem to present a certain "difficulty" in having children. The continuous need to have a child (insatiable, because it is not directed toward what it expresses) is addressed toward medicine and occupies the place of the object of lack. The game of Having replaces that of Being and allows such women to remain in the position of passage, in a structure strongly marked by a fetishist trend, which occupies the demand for love addressed to the mother. Contrary to the Freudian position, where having a male child allows the woman to eventually resolve her Oedipus complex, our clinical material shows that, in these cases, the so-called "desire to have a baby" responds to a refusal to subjectivize the lack. This refusal to "become a woman" is manifest as a fetishist position.

Key words: Fetichism, female subjectivity, "Desire of have a baby" 